\title{
Hyaluronic acid injection for sustained control of bleeding from a sclerotic ulcer base
}

A 55-year-old man with recurrent duodenal ulcers presented to our institution with massive hematemesis. Emergent endoscopy revealed a duodenal ulcer scar and pulsatile bleeding at the base of the ulcer $(\bullet$ Fig. 1).

Endoscopic hemoclipping was attempted three times, but this failed due to the sclerotic ulcer base. Thermocoagulation was tried but this also failed. Intense electrical coagulation of a duodenal lesion can cause perforation, so we carried out hot biopsy forceps coagulation three times. Injection of an epinephrine mixture around the bleeding focus only had a transient effect. However, prior to considering emergent surgery or radiological intervention, we decided to inject a total of $20 \mathrm{~mL}$ of a $0.2 \% 3000 \mathrm{kDa}$ Line 16 hyaluronic acid solution made from $4 \mathrm{~mL}$ Hyruan Plus (LG, Seoul, Korea) and $16 \mathrm{~mL}$ normal saline; $5 \mathrm{~mL}$ of the hyaluronic acid solution was injected at each of four points around the bleeding focus ( $\bullet$ Fig. 2). This intervention successfully stopped the bleeding ( Fig.3), and a follow-up endoscopy 12 hours later revealed no evidence of hemorrhage from the previously bleeding site ( Fig.4). Endoscopic ultrasonography after 3 days showed a round but illdefined, homogeneously hypoechoic lesion within the wall of the duodenum ( $\bullet$ Fig.5), which may have represented residual hyaluronic acid under the ulcer.

The disadvantages of injection therapy include a short-lived effect due to gradual dissipation of the injected fluid [1]. However, injection of hyaluronic acid solution increases the tamponading pressure and prolongs the tamponading time even under a sclerotic ulcer base. Hyaluronic acid is a naturally occurring polysaccharide with distinct physicochemical properties that underpin its application as a viscoelastic tool [2]. It is thought to be the best material for injection for endoscopic submucosal dissection because of its ability to create a persistent submucosal cushion [3]. Control of bleeding by sustained tamponading pressure allows sufficient time for inducing natural healing of the bleeding focus. Based on our experience, we suggest using, in carefully selected cases, hyaluronic acid injection for uncontrolled

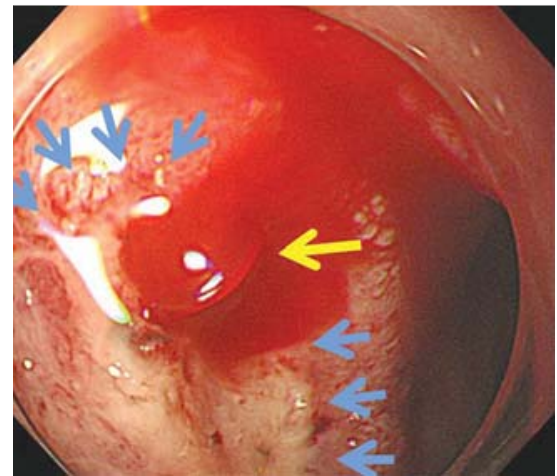

Fig. 1 Pulsatile bleeding (yellow arrow) from a sclerotic ulcer base (blue arrows) in a 55-yearold man with recurrent duodenal ulcers and massive hematemesis.

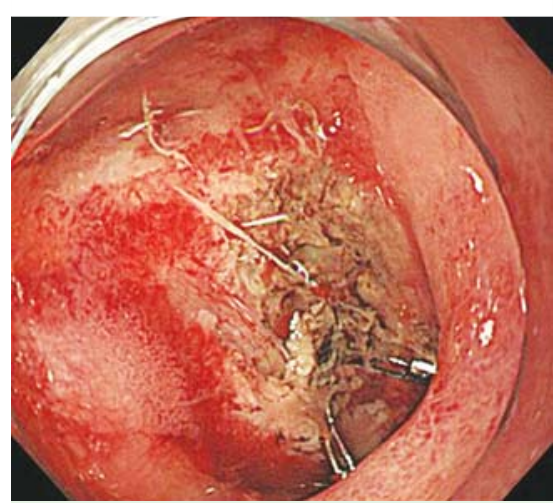

Fig. 3 Bleeding from the ulcer successfully controlled after hyaluronic acid injection.

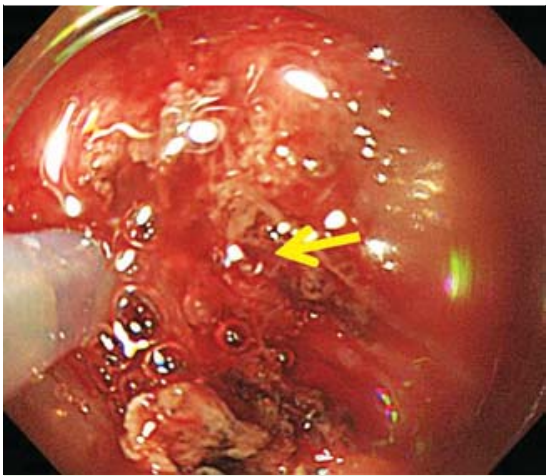

Fig. 2 Injection of $5 \mathrm{~mL}$ of $0.2 \%$ hyaluronic acid solution at the 9 o'clock side of the bleeding focus (arrow).

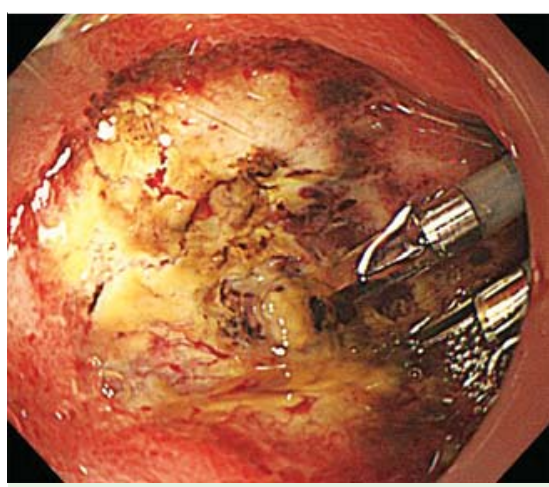

Fig. 4 Bleeding from the ulcer is still controlled after 12 hours following the hyaluronic acid injection.

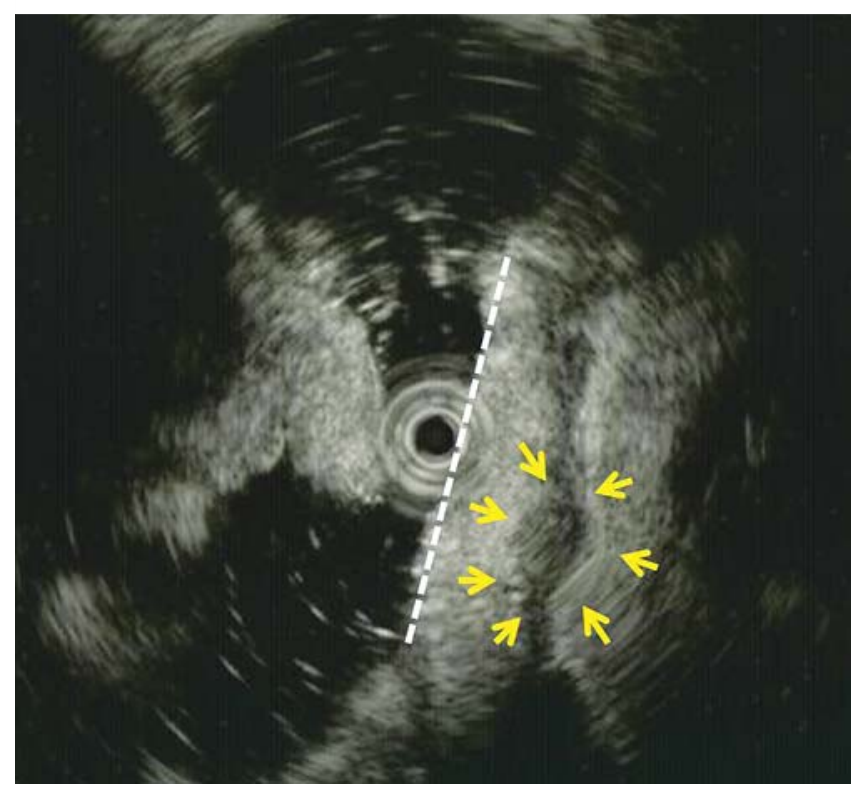

Fig. 5 Endoscopic ultrasonography (20 MHz, mini-probe) showing a relatively round but ill-defined, homogeneously hypoechoic lesion, suggesting residual hyaluronic acid (yellow arrows) under the ulcer base (white dotted line). 
bleeding from a sclerotic ulcer base, especially at the duodenum.

Endoscopy_UCTN_Code_TTT_1AO_2AD

\section{Competing interests: None}

\section{H. H. Kim, S. J. Park, M. I. Park, W. Moon}

Department of Internal Medicine, Kosin University College of Medicine, Busan, Korea

\section{References}

1 Park WG, Yeh RW, Triadafilopoulos G. Injection therapies for nonvariceal bleeding disorders of the GI tract. Gastrointest Endosc 2007; 66: 343-354

2 Goa KL, Benfield P. Hyaluronic acid. A review of its pharmacology and use as a surgical aid in ophthalmology, and its therapeutic potential in joint disease and wound healing. Drugs 1994; 47: 536-566

3 Hyun JJ, Chun HR, Chun HJ et al. Comparison of the characteristics of submucosal injection solutions used in endoscopic mucosal resection. Scand J Gastroenterol 2006; 41: $488-492$

\section{Bibliography}

DoI http://dx.doi.org/

10.1055/s-0031-1291756

Endoscopy 2012; 44: E169-E170

(c) Georg Thieme Verlag KG

Stuttgart · New York

ISSN 0013-726X

\section{Corresponding author}

\section{H. H. Kim}

Department of Internal Medicine Kosin University College of Medicine 34 Amnam-dong, Seo-gu

Busan 602-702

Korea

Fax: +82-51-990-5055

drhhkim@gmail.com 